\title{
THERAPEUTIC THYMECTOMY THE INTENSIVE POSTOPERATIVE CARE OF THE SEVERE MYASTHENIC PATIENT ${ }^{1}$
}

\author{
J H Harland M.B., B CH, and C. R. Stephen, M D ${ }^{2}$
}

INTEREST in therapeutic thymectomy as a means of treating myasthenı gravis has been rekindled in the last few years Much of the credit for preserving surgical interest in this procedure must go to Keynes (1), who has advocated the value of thymectomy consistently over many years

The patient in remission, with mild symptoms, and on a small dose of anticholmesterase drugs, will present postoperative problem; little out of the ordinary Although this type of case is considered most suitable for surgery, it is also the clinical type which will be referred for operation least often. The patient liable to give trouble is the one who is deteriorating, who requires increasing doses of drugs, and in particular whose respiratory muscles are affected. This paper will limit discussion to patients in the latter group, especially those in whom it is necessary to institute artuficial ventilation, and in whom problems of drug dosage arise The over-all management of anaesthesia in the myasthenic patient has been considered in detall by Chang et al (2) and also by Matthews and Derrick (3)

We may consider care in the immediate postoperative period under three headings (a) maintenance of adequate alveolar ventılation, (b) supportive therapy with anticholinesterase drugs, (c) other adjuvant therapeutic measures

\section{VENTILATION}

Reviewing the mortality in his early series, Keynes wrote in 1949, "The cause of death in almost all instances was due to pulmonary complications" (4). The keynote of postoperative care today remains the avoidance of respiratory complications. Should they occur, therapy must be instituted at once with energy and initiative

\section{Adequacy of Ventilation}

The adequacy of spontaneous respiration should be assessed by the anaesthesiologist immediately after operation. If it is believed that respiration is not adequate, consideration should be given to the immediate institution of intensive postoperative care. Even when the tidal volume appears adequate at the rnmediate termination of surgery, constant observation is necessary, because ventilation may deterrorate rapidly owing to pneumothorax, the accumulation of large quantities of secretions which the patient is too weak to cough up, or the development of atelectasis and pneumonia. The respiratory tract is particularly prone to be deluged with secretions when anticholinesterase therapy is started.

1From the Division of Anesthesia, Duke Medical Center, Durham, North Carolina

2Department of Anaesthesia, University Hospital, Saskatoon, Sask 


\section{Tracheobronchual Toilet}

The importance of effective bronchial cleansing cannot be overstressed The absence of audible evidence of mucus does not eliminate the possibility of bronchial obstruction. Too casual, too infrequent or too cautious use of the suction catheter can be detrimental A gradually rising pulse rate has been found to be of help in determining when aspiration is advisable. In the circumstances under consideration we have noticed a tendency for secretions to dimmish during sleep. As might be expected, the left lung wwll usually present more of a problem than the right Where the patient can tolerate the manceuvre, it is helpful to turn him intermittently on the right side to allow drainage of a suctioninaccessible left bronchial tree. The use of detergents such as "Alevaire" and more recently "Tergemist" has also been found to be of assistance to loosen secretions.

\section{Tracheotomy}

When ventilation becomes inadequate or when stubborn secretions are creating respiratory obstruction, a tracheotomy should be considered at once, rather than as a late, last-dutch resuscitative measure. Although tracheostomy may affect patient morale in a negative fashion and although it is not 1 deal to locate a potentially infected focus near a sternum-splitting incision, yet this procedure may be mandatory to save a patient's life. A tracheotomy is indicated when adequate tracheobronchial tollet can only be performed by this means and when the reduction of dead space will allow more adequate respiratory exchange in the patient with weakened intercostal muscles

\section{Mechanical Augmentation of Respiration}

If the weakened respiratory muscles are unable to provide adequate alveolar ventilation, that is, adequate tidal and minute volumes, assistance to respiration may be provided by a mechanical respirator The successful use of a tank respirator in such cases has been described $(2,7)$. However, thrs type of ventilator has limitations. Nursing difficulties are increased because of the essential structure of the unit. Furthermore, the patient has the most unpleasant sensation of being three-quarters encoffined.

The authors have seen such patients handled with the Drinker-Collins respirator and also the Jefferson ventilator. The latter or a prototype has appeared to offer advantages in the circumstances under consideration $(5,6)$. For example, when the myasthenic patient retains the ability to write, despite deficient ventilation, the Jefferson ventilator allows continual communication with the physicians and nurses.

Both these methods force the patient to adjust his respiratory rhythm to that of the machine Ability to do so without difficulty is variable. Pask has described the use of a respiratory assistor which is patient-triggered and actuvated without an initial respiratory effort The myasthenic patient described by Pask and his associates (6) was carried almost continuously on such a machine for a total of six weeks, with a successful outcome.

The patient may be allowed to breathe room air, oxygen-enriched aur, or a 
helium-oxygen mixture. The latter is particularly useful in the presence of respiratory obstruction As in any other similar circumstances, the use of 100 per cent oxygen should be avoided lest the syndrome known as "oxygen-poisoning" occur (8).

\section{Anticholtnesterase. Drugs}

Since 1934, when Walker first used physostigmine in treatıng myasthenı gravis, a number of products have been recommended and enjoyed some degree of therapeutic popularity. One group acts by "irreversible" poisoning of the cholmesterase system, e g, DFP. They are little used clinically. Most of the remainder have a dual action, consisting of an acetylcholine-like effect on the myoneural junction, together with "temporary" anticholınesterase activity. The relative importance of these complementary effects varies. physostigmine has no acetylcholine-like action, while edrophonum ("Tensılon") has a relatively weak anticholinesterase effect Neostigmine exerts its action in both ways Although neostigmine only will be referred to in the ensuing, discussion, similar considerations apply to other anticholinesterase drugs.

In over twenty years of use as a specific in myastheria gravis therapy, the ability of neostigmine to increase the muscle power of the patient has been noted repeatedly. In addition to this beneficent nicotinic activity, it also potentiates and imitates the muscarine-like effects of acetylcholine. Of the associated sinister effects following neostigmine administration, primary concern here is with the copious increase in salivary and bronchial secretions. Although these effects are usually inhıbited by atropinization, the belladonna drugs, while inhibiting secretions, at the same time make those secretions thick, viscid and stubbornly tenacious. It is believed better, perhaps, to sacrifice the advantages of atropmization and allow more efficient drainage and aspiration of secretions. The skeletal muscle effects of neostigmine are not completely understood. In some cases of this disease, it has been noted that irreversible changes take place in some muscle groups, particularly those of respiration $(1,6)$. That this group should be invidiously selected is perhaps not surprising since they alone of the skeletal muscles have been in continuous use since birth.

It has further been observed that a dose of neostigmine, which successfully improves skeletal muscle power generally, sometimes induces, paradoxically, further weakness of the respiratory muscles.

Although increasing the dose of neostigmme implements the power of myasthenic muscles, it does so only up to a point, beyond which further weakness occurs. Clinical improvement plotted against dose thus shows a linear increase over a short inital part of the curve, but subsequently drops to or below the baseline.

The pathogenesis of this development is understood easily by the anaesthesiologist as being analogous to the action of succinylcholine. Acetylcholine builds up to a certain optimum point, at which it can cause an action potential at the end plafe, despite the presence of the postulated curare-like metabolite. Further increase of acetylcholine causes prolonged falure of repolarization, with resultant paralysis. 
The improvement-deterioration point in the myasthenic patient is not always easy to determine clinically, especially in the immediate postoperatıve period when neostigmine requirements vary unpredictably Assessing the dosage of anticholinesterase drugs in this situation is somewhat similar to the difficulties inherent in trying to contiol the diabetic patient with insulin, wathout the benefit of blood sugar determmations. The most useful method of making a differentiation is the edrophonıum ("Tensilon") test.. Usually the response to the intravenous injection of $10 \mathrm{mg}$. of edrophonium is interpreted easily Transitory improvement indicates that neostigmine dosage is still below the critical level, whereas further deterioration indicates excessive administration of neostigmine However, the test is not infallıble in all cases, since patients vary in therr response to individual members of the anticholinesterase group of drugs, including edrophonium. The reverse response of certain muscle groups has already been mentioned.

The concomitant use of atropine may mask overdosage of neostigmine by camouflaging the muscarmic elements of the "cholnergic crisis" (9)-pin-point pupils, mcreased perıstalsis, nausea, movement of the bowels, urgency of micturation and hypersecretion The facial fasciculations usually seen in such a crisis are not a dependable sign masmuch as the severe myasthenic usually farls to demonstrate fasciculation, even on arterial injection of neostigmine In this connection the use of a neostigmine drip during surgery, as is sometimes advocated, appears to be of doubtful benefit It can add nothing to the facllity of surgery, but is capable of introducing a number of complications into postoperative management. It may actually cause deterioration of muscle power

\section{Development of a Drug-Refractory State}

Relative refractoriness may develop to one member of the antichohnesterase group of drugs, necessitating a change to another specific drug Such refractoriness is very likely to develop in the immediate postoperatıve perıod when drug requirements may be increased (3) and further deterioration of status precipitated by pulmonary infection In some instances the "refractory" state has proved on hindsight to have been in fact due to overdosage Familiar as the improvement-deterioration concept may be to the anaesthesiologist, one can understand easily how the situation may be confused in the immediate postoperative perod and the neostigmine syringe wielded with an overgenerous hand

Where the status of the patient has become uncertain, it is advisable to obtain breathing space for both attendants and patient by stopping neostigmine and instituting artificial respiration (10) The régime should be altered for a period sufficient to ensure the elımmation of neostıgmine already administered (6). Ordinarily parenteral neostigmine becomes ineffective in about six hours. A period of twenty-four hours should be more than adequate to obtain a drug-free baselme Griffin et $a l$, however, have suggested that where oral neostigmine has been used it may be necessary to omit the drug for a week (6) Beginning twenty-four hours after cessation of specific treatment, the "Tensilon" test will indicate'whether neostıgmine therapy will again be of value. The measiurement 
of tidal volume and inspiratory capacity before and after edrophonium is of help in assessing the improvement which is likely to result from remstitution of neostigmine therapy.

Churchill-Davidson and Richardson (10) have recently successfully used d-tubocurarme as a further means of giving the end-plate a "rest" and restoring sensitivity to neostigmine. They postulate that variations in end-plate response to neostigmine are due to variations in the ratıo of acetylcholine and cholıne molecules The former causes depolarization and the latter a competitive type of block Curare acts by mcreasing the threshold of excitation of the end plate, thus giving it a "rest"

Once neostigmine therapy has been reinstituted, it should be possible to use the ventilator intermittently and gradually to wean the patient from it altogether Although it should be possible to predict whether the patient will do well, off the respirator certain difficulties may develop Keynes (1) has described the "pseudo-recovery" of the postoperative patient, desperately anxious not to hurt the feelings of the surgeon by falling to manifest immediate improvement. As in the patients with poliomyelitis described by Holland and Coles (11), denial of illness may be present as a psychological defence mechanism. Pask has described an ingemious method to distinguish dyspnoea due to hypoventilation and that due to psychic dependence on the ventilator. It was found possible to determine the patient's iespiratory status objectively by introducing a sleep concentration of nitrous oxide into the imput of the ventilator, thus elimmating the functional, component $(\underset{6}{6})$

\section{Sedation and Patn Relief}

As a basic pinciple, it is best to avord the use of respiratory depressant drugs in myasthenia However, if the patient is being adequately ventilated mechancally, the force of the aigument against the use of narcotics is much weakened Gilfin et al (6) have used "liberal" quantities of narcotics and barbiturates $m$ the immediate postoperative peiıd without ill effect An exhausted patient has been carred successfully for a period of eight hours on very light nitious oxide anaesthesia We have found this technique provided a badly needed, sustaned, restful sleep By momentanly disconnecting the patient from the ventılator and source of gases, an adequate brondhial torlet could be carred out without the patient becoming fully conscious

\section{Other Therapeutic Meastines}

\section{Adjuvant Drug Therapy}

Durmg the period of inadequate ventilation various respuatory stimulants have been utlized Pask (6) was unimpressed with the effects of light ether anaesthesia, lobeline and amphetamme. In ou limited expenence ephedrme, traditionally an adjuvant to specific therapy $m$ myasthenia, has, been of no specific value. The indications for the therapeutic doses of specific antibiotics are evident. 


\section{General Nursing Care}

At both this and other centres -(2) it has been found advisable to retain these patients in the recovery room as long as intensive care is needed. In this location are to be found both adequate facilities and personnel to treat respiratory complications as they arise, The relative immobility of the patient demands attentive bed care (6).

\section{Nutrition and Fluid Balance}

Dysphagia is often present, but patients can be fed successfully through a stomach tube. Fluid requirements must meet ordinary daily needs, plus an addition to make up for increased salivation and bronchorrhea. Broth fed through a stomach tube should contain enough potassium to avoid a negative potassium balance. The development of the latter would tend to aggravate muscle weakness.

\section{The Importance of Team Work}

This point has been stressed in the past by Griffin et al. (6) and also by Matthews and Derrick (3). The intensive postoperative care of the myasthenic following thymectomy is a problem requiring the combined skills of the internist, the surgeon, the anaesthesiologist and the nursing staff.

\section{Support of Patient Morale}

These individuals are often depressed prior to surgery. They have been made aware of a relatively poor prognosis and have often had the frustrating experience of being accepted as neurotics by their doctors and families for a long period prior to diagnosis. They may appear to take the surgical procedure well and remain surprisingly cheerful despite a tracheotomy. Once the excitement has passed off and, from the attendant's point of view, order is beginning to appear from chaos, an acute depressive reaction may occur: At this point an assumed omnipotence by the doctor will tend to favour recovery. "The single most important factor that the environment must offer is HOPE" (12).

\section{Illustrative Case}

Thymectomy was performed on a 24-year-old myasthenic female whose symptoms had started three years prior to operation. Initially symptoms had been mainly ocular, but subsequently dysphagia and dysphonia developed. Prior to surgery she was taking Mestinon, $120 \mathrm{mg}$., and Mytelase, $10 \mathrm{mg}$., every three hours. In spite of this therapy considerable weakness of the respiratory muscles was present. Preoperatively the vital capacity was 1.9 litres (61.4 per cent of predicted normal) and the maximum breathing capacity was 36.4 litres (42.6 per cent of predicted nornal). At surgery, which was uneventful, a small thymus showing diffuse hyperplasia was removed.

The postoperative course was stormy due to generalized weakness and resultant inability to clear secretions. A basal pneumonitis developed and the patient appeared to become refractory to neostigmine, which was given by slow intravenous drip after operation. Neostigmine therapy was discontinued and Mestinon and Mytelase by gastric tube were substituted. However, two days postoperatively, she became dyspnoeic and the pulse rate rose. It was believed that she was exhibiting a true "myasthenic" crisis with drug refractoriness, rather than a "cholinergic" crisis. A tracheotomy was performed and a cut-off cuffed endotracheal tube inserted into the trachea. The patient was respirated with a Jefferson ventilator using a fifty-fifty mixture of helium and 
oxygen. All specific anticholinesterase therapy was discontinued Ventulation was performed artificially for three days, at first continuously and later intermittently. The respiratory musculature of the patient was so weak that there was little opposition to the pattern of respiration imposed by the ventilator During the second night lizht nitrous oxide anaesthesia was employed to give the patient a much needed rest. Ater 72 hours and an encoulaging "Tensilon" test, Mestınon therapy was resumed, a silver cannula inserted in place of the short endotracheal.tube and the patient returned from the recovery loom to the ward.

She was discharged fifteen days after surgery on Mestınon, $60 \mathrm{mg}$, every three hours, $1 \mathrm{e}$, half the preoperative dose It was believed that some immediate evidence of improvement could be assumed in this patient

\section{SUMMARY}

The care of the post-thymectomy myasthenic patient who develops respiratory complications and in whom problems of drug dosage arise is considered It is believed that intensive postoperative care is necessary under these circumstances, including tracheostomy, institution of artificial ventilation and the temporary cessation of anticholınestes ase therapy. Problems of management a1e discussed and a case is presented.

\section{RÉSUMÉ}

Nous avons étudié les soins postopératorres du malade myasthénique thymectomısé chez qui apparaissent des complications respiratoires et chez qui surgissent les problèmes de dosage de médicaments Nous avons la conviction que, dans ces circonstances, il faut prodiguer des soins postopératoires intensifs dont la trachéotomie, la ventılation artıficielle et la cessation temporaure de la thérapeutıque antıcholınestérasıque Nous avons présenté un cas et exposé les problèmes que cela pose.

\section{REFERENCES}

1 Kerves, G Surgery of the Thymus Gland Second (and Thurd) Thoughts Lancet 1 1197 (1954)

2 Chanc, J, Harland, J H, \& Graves, H B Anesthetic Aspects of Thymectomy for Myasthenia Gravis Canad. Anaesth Soc J 413 (1957)

3 Matthews, W. A, \& Derrick, W S Anesthesia in the Patient with Myasthenua Gravis Anesthesiology 18443 (1957)

4 KeYnes, G" Thymectomy in Myasthenı Gravis Brit M J 2612 (1949)

5 B ऊøRK, V D., \& Engstros, C G Treatment of Ventilatory Insufficiency by Tracheostomy and Artificial Ventilation J Thoracic Surg 34228 (1957)

6 Griffin, S G, Natiras, F J, \& Pask, E A Thymectomy dunng Respuratory Failure in a Case of Myopathy with Myasthenia Gravis Lancet 2 704 (1956)

7 Jørgenson, J B, \& Merurison, F R Thymectomy in the Treatment of Myasthenua Gravis Acta chir Scandinav 107414 (1954)

8 Comroe, J H, H Dripps, R D The Physiological Basis of Oxygen Therapy First edition Springfield, Ill. C C Thomas (1950)

9 Goodman, L S., \& Gilican, A The Pharmacological Basis of Therapeutics. Second edition New York, Macinillan (1955) chaps 21 and 33

10. Churchill-Davidson, H C, \& Richardson, A. T. Myasthenia Crisis Therapeutic Use of d-Tubocurarme. Lancet I 1221 (1957).

11 Holland, J. C B, \& Coles, M R Neuropsychiatıc Aspects of Acute Poliomyelitis Am J Psychiat 11454 (1957)

12 Prange, A J, \& Base, D W Psychic Events Accompanying an Attack of Poliomyelitis Brit J Med, Psychol. 30 (2) 75 (1957). 